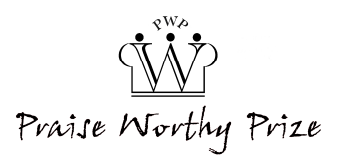

\title{
Complementary Interleaved CDS Arrays to Improve Antenna Aperture Utilization
}

\author{
Bambang Dewandaru, Fitri Y. Zulkifli, Eko T. Rahardjo
}

\begin{abstract}
Volume usage is an important issue in space-based satellite communication systems. In this paper, antenna array elements are interleaved into one aperture in order to avoid using two separated antennas. The method utilizes two complementary cyclic difference set (CDS) arrays, where equal array element excitations reduce the complexity of the driving network and improve the efficiency of its direct current-to-radio frequency power conversion. Adding elements to each array member and placing them in symmetry with respect to the origin at distances arranged to form an equivalent amplitude using Hamming and cosine squared taperings decrease the side lobe levels and beam widths. The amplitude-to-space conversion is achieved through an equal area approximation. The results demonstrate the effectiveness of the proposed method in interleaving two arrays sharing one aperture for two beam antennas, each one with a narrowed beam width and decreased side lobes. The proposed method offers antenna design flexibility for a given aperture size despite the limited number of CDSs. The measurements demonstrate that compared to the original CDS performance, the arrays have a narrower beam width of at least 3 degrees and a lower side lobe level of at least $1.66 \mathrm{~dB}$, with a difference of less than $0.9 \mathrm{~dB}$ between simulations and reality. Copyright $(2019$ The Authors.

Published by Praise Worthy Prize S.r.l.. This article is open access published under the CC BY-NC-ND license (http://creativecommons.org/licenses/by-nc-nd/3.0/).
\end{abstract}

Keywords: Cyclic Difference Set, Equal Area Approximation, Interleaved, Sparse Array, Aperture Sharing

\section{Nomenclature}

CDS

V

$A_{T}(x)$

$A_{O}(x)$

$A_{C}(x)$

$y_{H}$

$y_{S \operatorname{Cos}}$

$x_{o}$

$\delta(x)$

$d_{\text {min }}$

$n$

$l$

$a_{n}$

$\bar{a}_{n}$

$m$

$m_{o}$

$m_{c}$

$s_{i}$

Cyclic Difference Set of array

Original CDS array

Complement CDS array

Hamming taper function

Grid uniform distance

Dirac delta function avoid overlap

Array element number

total number of sub area the original CDS set
Total CDS length in number of elements

Truncated version of an unlimited length

Squared cosine taper function

Minimum distance between the elements to

Aperture total length of the CDS array

Member of the complementary CDS

Member of the complementary CDS

Total number of improvement elements to

Total number of improvement elements to the complement CDS set

Distances from origin of the $\mathrm{i}^{\text {th }}{ }^{\text {element }}$ ef the improvement set to the original CDS

$\begin{array}{ll}s_{j} & \begin{array}{l}\text { Distances from origin of the } \mathrm{j}^{\text {th }} \text { element of } \\ \text { the improvement set to the CDS } \\ \text { complement }\end{array} \\ \text { int } & \begin{array}{l}\text { Integral function in the MATLAB } \\ \text { fzero }\end{array} \\ \text { VSWR } & \begin{array}{l}\text { Fzero function in the MATLAB } \\ \text { Voltage Standing Wave Ratio }\end{array} \\ U & \text { Utilization of the aperture } \\ l_{p} & \text { Length of a single patch } \\ L & \text { Total length of the interleaved array } \\ N & \text { Total number of antenna elements } \\ \text { EIRP } & \text { Equivalent Isotropic Radiated Power }\end{array}$

\section{Introduction}

Smaller satellites are always in demand due to the limited cargo space in a space transporter. An array antenna can potentially take up only one-third of the space taken up by a satellite parabolic reflector antennas, thereby providing the same amount of functionality occupying much less space. The exponential growth of telecommunications traffic has necessitated better utilization of the frequency band. Utilization of the frequency spectrum can be expressed as its traffic carrying capacity (bit/Hz/ $/ \mathrm{km}^{2}$ ), leading to a quest for multi-beam radiation from an aperture antenna. There are several ways to form multi-beam radiation, such as 
multiple horns on a common parabolic reflector, multiple horns with lenses, and directly radiating antenna element arrays. The latter can provide multiple beams of multiple sub-arrays within an aperture [1]-[7]. Sparse array antenna element placement enables many arrays to share an aperture, as the portion of the aperture that is not used may be utilized for other antenna arrays so that several arrays can share a single aperture. The sparse placement advantages include a decrease in the total number of required elements and the avoidance of grating lobes through a break in periodicity. The sparse placement disadvantages include a wider beam width, less efficient use of the aperture, which causes a decrease in the maximum EIRP, limited control of the shape of the radiation pattern, and a loss of the regular building block array that enables easier manufacturing [8]-[15]. Two strategies for placing the elements of an array are separate physical sub-division placement of the array elements and interleaved placement. The advantages of sub-division by area separation are the ability to achieve minimum interference between array members and the possibility of the utilization of established array design strategies. The disadvantage of sub-division by area separation is the difficulty of achieving a highly directive pattern due to the relatively limited availability of aperture space. In an interleaved design, the entire aperture can be exploited, and collocation of the phase centres of the array can be realized at the expense of a more complex design and a possible increase in the interference between sub-arrays [16]-[19]. In satellite communications, uniform amplitude excitation of the antenna elements is desirable both to achieve efficient operation of the power amplifiers and to simplify the driver network. This simpler arrangement also leads to higher system reliability. In this case, a particular pattern of illumination density can be obtained by the utilization of varying distances between the elements of the array antenna [20], [21]. Swenson has reported on a method for improving the side lobe level in a regular uniform interelement distance for a linear array in order to construct a radio astronomy telescope. A square cosine taper was utilized to improve the side lobe level of an array antenna, but this taper is applied to only one beam radiation pattern [22].

Leeper has demonstrated the usage of a cyclic difference set (CDS) in order to construct arrays with equal amplitude excitation for non-equal inter-element distances. CDSs can generate thinned arrays that have a predictable gain with a lower side lobe level. A ' 1 ' on the set represents the presence of an antenna element, whereas a ' 0 ' represents its absence.

When compared to random placement, the autocorrelation of the CDS is maximized, and therefore, a better side lobe level can be achieved. Furthermore, Leeper has showed that the complementary CDS also inherits the same performance as the CDS [23]. Rahardjo et al. [15] have demonstrated a method for improving the side lobes of CDS arrays by arranging two similar arrays to achieve higher illumination density in the middle of the apertures to produce nearly Taylor-optimal distribution. Trampuz et al. [24] demonstrated improvements in side lobe performance through a complex arrangement of complimentary CDS arrays, where one sub-array is used for the transmission of an FMCW radar and its complement array is used in order to receive the returning radar signal. In this arrangement, the complementary arrangement has resulted in a better side lobe performance than for an individual member.

However, the improvement methods have been applied to only one beam per aperture [24]. Chun-Xu Mao et al have shared antenna aperture with uniform distances arrays where addition of number of elements will requires amplitude tapering in order to get optimum results [25], [26]. The above mentioned methods are tabulated in the Table I.

TABLE I

APERTURE UTILIZATION METHODS

\begin{tabular}{cc}
\hline Authors & Results Of The Method \\
C.-X. Mao et al. [25], [26] & $\begin{array}{c}\text { Two array and three arrays sharing one } \\
\text { aperture, the array have uniform distance } \\
\text { between array's elements. } \\
\text { One array per aperture, limited set CDS only, } \\
\text { uniform excitation, elements are placed at } \\
\text { the center of aperture, realatively difficult to } \\
\text { interleaved. }\end{array}$ \\
Rahardjo et al. [15] & $\begin{array}{c}\text { One radiation per aperture only, no } \\
\text { interleave, non-uniform distance between } \\
\text { array elements, therefore aperture is less } \\
\text { utilized }\end{array}$ \\
Twenson [22] & $\begin{array}{c}\text { Two radiation pattern of two arrays in } \\
\text { interleaved manner from one aperture, } \\
\text { uniform excitation, limited set of CDS only. } \\
\text { One combined radiation pattern from two } \\
\text { arrays in interleaved manner, limited set } \\
\text { CDS only }\end{array}$ \\
Trampuz et al. [24] &
\end{tabular}

Utilizing both the CDS and its complement in an interleaved manner for the antenna aperture has largely filled the available space and it has avoided the grating lobe by breaking the periodicity of the antenna element placement. In this paper, a method for improving the radiation pattern of the two interleaving CDS arrays by sharing one aperture by utilizing both the CDS and its complement in an interleaved manner for the antenna aperture largely filled the available space and avoided the grating lobe by breaking the periodicity of the antenna element placement is presented. A CDS has been used in order to construct interleaved aperture sharing arrays, thus guaranteeing the filling of the majority of the inner side of an aperture of a linear antenna by utilizing its complementary set and adding more elements to the outer part of the aperture to reduce its side lobe level and beam width.

While an opportunity for a more complex one can be considered, in order to form the array simple low cost patch antenna elements are used here [27], [28].

The paper is organized as follows. Proposed design methodology and design implementation, and simulation, are presented in Section II. Realization and measurement of the manufactured array and discussion are presented in Section III. Finally, Section IV illustrates the 
conclusions.

\section{Complementary Interleaved Array Design}

The designed array consists of the placement of CDS antenna elements and its complementary set in the middle part of the aperture. The added elements are placed in the outer region of the aperture and in symmetry with respect to the origin. In this manner, the position of the phase centres of the arrays are kept in the middle of the aperture and allow for the exploitation of the entire aperture length, resulting in a small angular width and maximum possible gain for the produced radiation pattern. The operating frequency has been chosen by considering that the transmitted power from the satellite is very limited and the very long distance between the transmitter and receiver results in high path loss attenuation. In addition, the frequency should be subject to low environmental noise. The distance between the array elements should not be less than the minimum distance dictated by the size of the antenna element in order to avoid overlapping between adjacent elements. Here, the allowable antenna elements sizes are smaller for a higher frequency.

\section{II.1. Design Methodology}

The design procedure is as follows. A CDS is chosen, and its median is identified and set as the origin point of the $\mathrm{x}$-axis. The minimum distance between the elements is chosen based on the dimensions of the planned array.

The aperture size is chosen and normalized to $-1 \leq x \leq 1$ of the length. Since additional elements are added and placed in symmetry with respect to the origin, only an even number of added elements can be used. The inter-element distances of the added elements are calculated via an equal area approximation. The illumination density has been calculated, based on unequal elements distances that are equivalent to the illumination density of an amplitude taper associated with regularly spaced elements. In this design, only additional elements that do not overlap with the CDS antenna elements are used. The same steps are repeated in order to add elements to the complementary CDS.

Thus, in this design, two aperture illumination densities are formed by two space tapered arrays in an interleaved manner. The grating lobe should be considered when the chosen regular distance is more than the half of the wavelength of the operating frequency. In this case, however, the grating lobe is no longer a dominant issue due to the break in the periodicity caused by the use of thinned arrays and irregularly spaced elements. The CDS minimum distance between antenna element $d_{\min }$ is set such that the interference between arrays is reduced [29]. The shape of the radiation pattern is justified by the fact that eight degrees of illumination should be provided in order to cover a geosynchronous orbit around Earth. Any excess degrees will provide radiation that will fall outside Earth. A CDS array is a truncated version of the unlimited length of the array and it can be represented as [23], [30], [31]:

$$
A_{T}(x)=\sum_{n=0}^{V-1} a_{n} \delta\left(x-n x_{o}\right)
$$

where $\delta(x)$ is the Dirac delta function, $V$ is the total CDS length, and $a_{n}$ is either " 1 " or " 0 " according to the CDS, where $n$ is the CDS element number. When CDS is placed symmetrically with respect to the origin, the CDS array shown in equation (1) can be rewritten as:

$$
A_{T}(x)=\sum_{n=0}^{V-1} a_{n} \delta\left(x-n x_{o}+\frac{l}{2}\right)
$$

where $l$ is the aperture length of the CDS array and $a_{n}$ is each member of the CDS array. The added elements have equal amplitudes and they are symmetrically arranged relative to the origin; however, they also have non-equal inter-element distances. The distances of the added elements are calculated in order to mimic an equivalent amplitude illumination taper. Two taper functions are utilized both to avoid an overlap between the added elements and to take advantage of their availability in the literature [32]. The first set of added elements utilizes the Hamming taper $y_{H}$. If it is used as an illumination distribution taper for an aperture, this taper provides the lowest first side lobe level and has a ripple nearly equal to that of the side lobe level. The taper linear distribution is formulated as:

$$
y_{H}=0.54+0.46 \cos \left(\frac{\pi x}{a}\right)
$$

where $x$ is the element coordinate, $2 a$ is the array length, and $y$ is the illumination density. The second taper uses a squared cosine taper function $y_{S C o s}$. If it is used as a radiation taper for an aperture, this taper has the smallest side lobe level compared to the triangle, cosine and uniform distributions because it has the smoothest distribution. This distribution is defined as:

$$
y_{S \operatorname{Cos}}=\cos ^{2}\left(\frac{\pi x}{2 a}\right)
$$

By employing two complementary CDSs and two illumination tapers, two interleaved arrays are constructed with a performance approaching the optimum achievable illumination density. The conversion from the above amplitude tapers to a space taper was has been performed using an equal area approximation. The array element distances have been derived by approximating a rationalized cumulative distribution for the illumination of the aperture. The 
illumination cumulative distribution have been divided by the number of the representative array elements, resulting in equal areas, as shown in Figs. 1. Thus, every array element represents a sub-area of the illumination cumulative distribution function. The distances of elements $s_{i}$ and $s_{j}$ approximate the equal area division of the cumulative distribution for the Hamming and the square cosine tapers consecutively and have been calculated by integrating the represented area under the related tapering function such that:

$$
\int_{\text {Subarea }} y(x) d x=\frac{2 \int_{0}^{a} y(x) d x}{m}
$$

where $m$ is the total number of sub area, $y(x)$ is the tapering function.

The MATLAB [33] software's int and fzero functions have been utilized to place the elements representing the midpoints of the representative area, as shown in Figs. 1.

For a CDS array length of $l, s_{i}$ and $s_{j}$ are the distances of the improvement array elements from the origin. Using these elements, we can write the original CDS array in equation (2) can be written as follows:

$$
A_{O}(x)=\sum_{n=0}^{V-1} a_{n} \delta\left(x-n x_{o}+\frac{l}{2}\right)+\sum_{n=V-1+m}^{V-1+m_{o} / 2} \delta\left(x \pm s_{i}\right)
$$

where $m_{o}$ is the total number of improvement elements added to the original CDS, and $s_{i}$ is the distance of the $\mathrm{i}$ th element of the improvement set. Combining the complement CDS array and its improvement elements with equation (2) yields:

$$
A_{C}(x)=\sum_{n=0}^{V-1} \bar{a}_{n} \delta\left(x-n x_{o}+\frac{l}{2}\right)+\sum_{n=V-1+m}^{V-1+m_{c} / 2} \delta\left(x \pm s_{j}\right)
$$

where $\bar{a}_{n}$ is a member of the complementary CDS, $m_{c}$ is the total number of improvement elements to the complement CDS, and $s_{j}$ is the distance of the $\mathrm{j}$-th element of the improvement set. The numbers $m_{o}$ and $m_{c}$ imply that the added improvement of antenna elements does not have to be similar. The radiation pattern from the array is a multiplication of the element factor with the array factor. The array factor is the Fourier transform of the autocorrelation of the array element position.

However, due to the additional improvement elements, which resulted in the loss of the aperture grid uniformity, a closed-form solution to equations (5) and (6) cannot be easily established, meaning that the available Fourier transform of the autocorrelation cannot be used. Therefore, simulations have been used to observe the resulting radiation pattern from the CDS array containing the additional improvement elements.

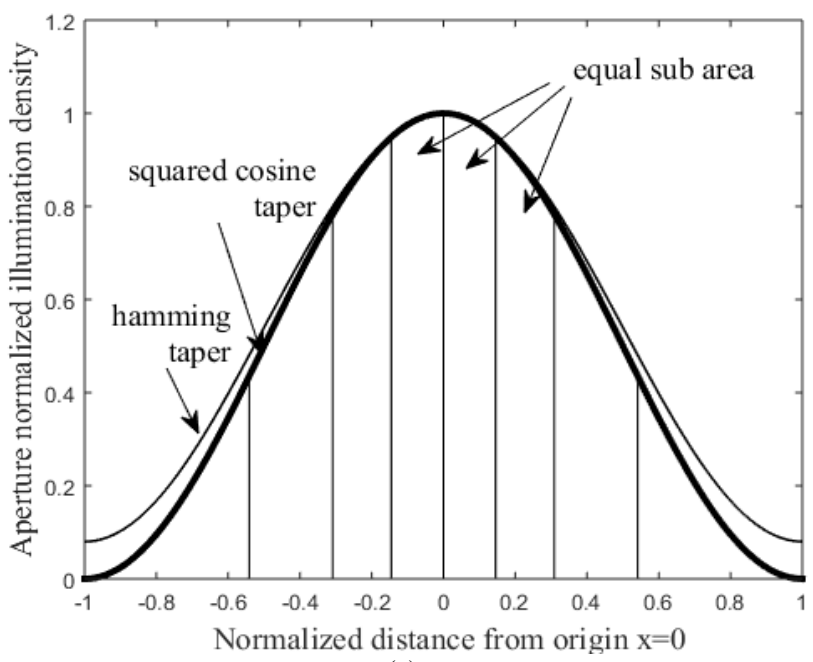

(a)

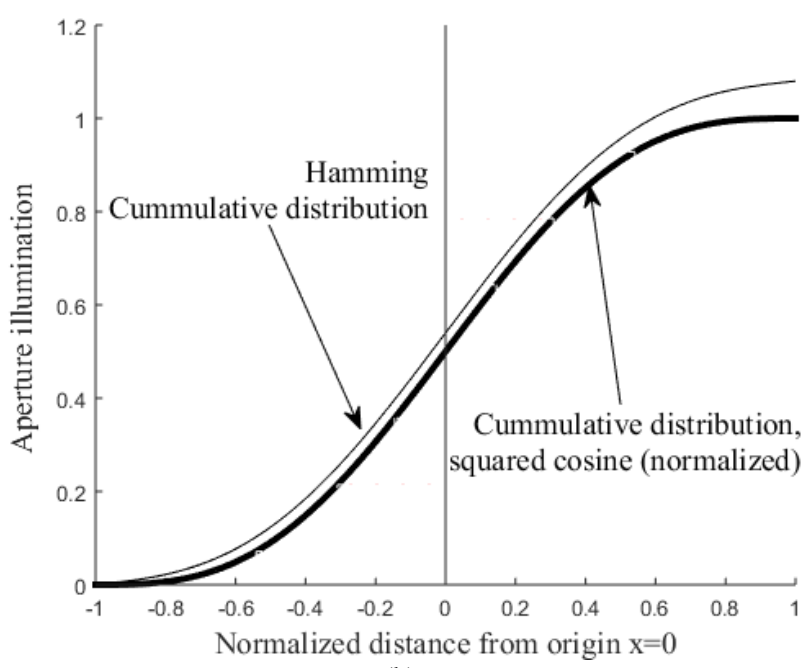

(b)

Figs. 1. Equal area approximation for distance determination

\section{II.2. Design Implementation}

An operating frequency of $4 \mathrm{GHz}$ has been used due to the low environmental noise at this level in the atmosphere. This low-noise condition is required due to the limited power of a satellite transmitter. Patch antennas has been used as antenna elements. Simulations of the arrays have been performed using computer simulation technology (CST) software. A $24.6 \mathrm{~mm} \times$ $24.6 \mathrm{~mm}$ square patch antenna element, $0.8 \mathrm{~mm}$ thick Taconic TLY 05 substrate has been designed. The patch provided a bandwidth of $49 \mathrm{MHz}$ in the $4 \mathrm{GHz}$ frequency band with a VSWR $<2$, a main lobe magnitude, a side lobe level of $-21.5 \mathrm{~dB}$, and $79.2^{\circ}$ of $3 \mathrm{~dB}$ angular width, as shown in Figs. 2. Five arrays have been constructed using the proposed method. Considering that the minimum distance $d_{\min }$ should be larger than the patch width, a regular grid for the CDS with $4 \mathrm{~cm}$ uniform distance has been employed. Five CDS have been used: 
CDS (11,5,2), CDS $(15,7,3), \quad$ CDS $(19,9,4), \quad$ CDS $(23,11,5)$ and $\operatorname{CDS}(31,15,7)$. The space tapering coordinates of the patches have been calculated for each array and they are shown in Table II. Six patches have been added and arranged in symmetry with respect to the origin. The total array length is greater than the original CDS length. Longer CDS lengths will have more influence on the total array radiation pattern.
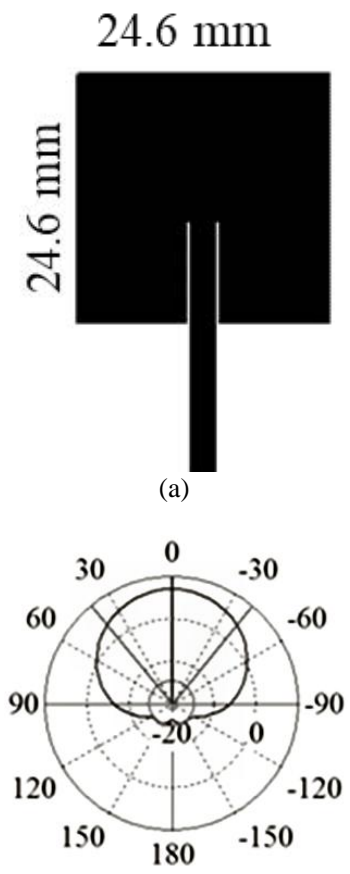

Theta / Degree vs. dB

(b)

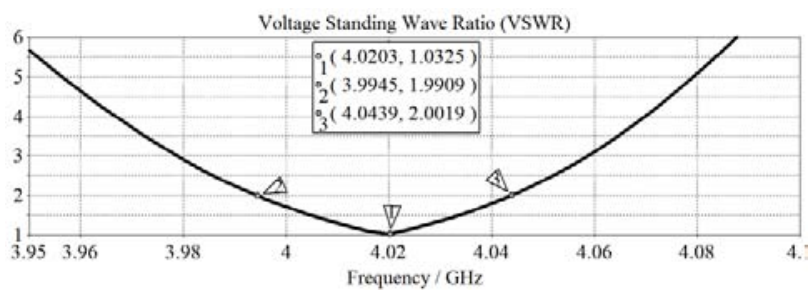

(c) Bandwidth $49 \mathrm{MHz}, \mathrm{VSWR}=2$

Figs. 2. Patch antenna and its radiation pattern: (a) Rectangular patch antenna. (b) Radiation pattern. (c) Bandwidth $49 \mathrm{MHz}$ at VSWR $=2$

\section{II.3. Array Simulation}

Figs. 3 show the CST software simulation results of the radiation patterns before and after the addition of the improvement elements. Table III presents a summary of the results. Only three out of five simulation results are presented here, with abbreviations that include Ori=original set and com=complement set, as depicted in The simulation results have showed that the addition of antenna elements to the CDS has been arranged to mimic the amplitude resulted in smaller angular widths, and the side lobes are decreased. A more substantial improvement can be achieved by adding more elements, resulting in a longer aperture size.
TABLE II

DISTANCES FROM THE ORIGIN $X=0$ OF

THE IMPROVED INTERLEAVED CDS ARRAY

\begin{tabular}{|c|c|c|c|c|c|c|}
\hline & $\begin{array}{l}\text { Element } \\
\text { Number }\end{array}$ & $\begin{array}{c}\text { CDS } \\
(31,15,7)\end{array}$ & $\begin{array}{c}\text { CDS } \\
(23,11,5) \\
\end{array}$ & $\begin{array}{c}\text { CDS } \\
(19,9,4) \\
\end{array}$ & $\begin{array}{c}\text { CDS } \\
(15,7,3) \\
\end{array}$ & $\begin{array}{c}\text { CDS } \\
(11,5,2) \\
\end{array}$ \\
\hline \multirow[b]{4}{*}{ ఏ્छ } & 21 & -1.27 & & & & \\
\hline & 20 & -1.15 & & & & \\
\hline & 19 & -0.91 & & & & \\
\hline & 18 & -0.84 & & & & \\
\hline \multirow{3}{*}{ 苛 } & 17 & -0.69 & -0.99 & & & \\
\hline & 16 & -0.64 & -0.87 & & & \\
\hline & 15 & -0.60 & -0.71 & -0.69 & & \\
\hline$\stackrel{\mathscr{E}}{\Xi}$ & 14 & -0.56 & -0.64 & -0.61 & & \\
\hline \multirow{4}{*}{ 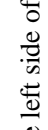 } & 13 & -0.52 & -0.53 & -0.53 & -0.68 & \\
\hline & 12 & -0.48 & -0.48 & -0.48 & -0.58 & \\
\hline & 11 & -0.44 & -0.44 & -0.43 & -0.48 & -0.58 \\
\hline & 10 & -0.40 & -0.40 & -0.39 & -0.42 & -0.51 \\
\hline \multirow{2}{*}{ 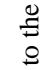 } & 9 & -0.36 & -0.36 & -0.36 & -0.37 & -0.41 \\
\hline & 8 & -0.32 & -0.32 & -0.32 & -0.32 & -0.38 \\
\hline \multirow{3}{*}{. } & 7 & -0.28 & -0.28 & -0.28 & -0.28 & -0.31 \\
\hline & 6 & -0.24 & -0.24 & -0.24 & -0.24 & -0.29 \\
\hline & 5 & -0.20 & -0.20 & -0.20 & -0.20 & -0.20 \\
\hline \multirow{4}{*}{$\underset{\forall}{\|}$} & 4 & -0.16 & -0.16 & -0.16 & -0.16 & -0.16 \\
\hline & 3 & -0.12 & -0.12 & -0.12 & -0.12 & -0.12 \\
\hline & 2 & -0.08 & -0.08 & -0.08 & -0.08 & -0.08 \\
\hline & 1 & -0.04 & -0.04 & -0.04 & -0.04 & -0.04 \\
\hline \multicolumn{2}{|c|}{ Origin $=0$} & 0.00 & 0.00 & 0.00 & 0.00 & 0.00 \\
\hline \multirow[b]{4}{*}{ ఏ્छ } & 1 & 0.04 & 0.04 & 0.04 & 0.04 & 0.04 \\
\hline & 2 & 0.08 & 0.08 & 0.08 & 0.08 & 0.08 \\
\hline & 3 & 0.12 & 0.12 & 0.12 & 0.12 & 0.12 \\
\hline & 4 & 0.16 & 0.16 & 0.16 & 0.16 & 0.16 \\
\hline \multirow{4}{*}{ 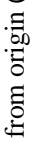 } & 5 & 0.20 & 0.20 & 0.20 & 0.20 & 0.20 \\
\hline & 6 & 0.24 & 0.24 & 0.24 & 0.24 & 0.29 \\
\hline & 7 & 0.28 & 0.28 & 0.28 & 0.28 & 0.31 \\
\hline & 8 & 0.32 & 0.32 & 0.32 & 0.32 & 0.38 \\
\hline \multirow{4}{*}{ 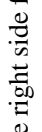 } & 9 & 0.36 & 0.36 & 0.36 & 0.37 & 0.41 \\
\hline & 10 & 0.40 & 0.40 & 0.39 & 0.42 & 0.51 \\
\hline & 11 & 0.44 & 0.44 & 0.43 & 0.48 & 0.58 \\
\hline & 12 & 0.48 & 0.48 & 0.48 & 0.58 & \\
\hline \multirow{2}{*}{$\begin{array}{l}\stackrel{\Xi}{\Xi} \\
\stackrel{0}{0}\end{array}$} & 13 & 0.52 & 0.53 & 0.53 & 0.68 & \\
\hline & 14 & 0.56 & 0.64 & 0.61 & & \\
\hline \multirow{4}{*}{ 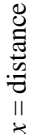 } & 15 & 0.60 & 0.71 & 0.69 & & \\
\hline & 16 & 0.64 & 0.87 & & & \\
\hline & 17 & 0.69 & 0.99 & & & \\
\hline & 18 & 0.84 & & & & \\
\hline \multirow[t]{3}{*}{5} & 19 & 0.91 & & & & \\
\hline & 20 & 1.15 & & & & \\
\hline & 21 & 1.27 & & & & \\
\hline \multicolumn{2}{|c|}{$\begin{array}{l}\text { Total Array } \\
\text { Length (m) }\end{array}$} & 2.55 & 1.97 & 1.39 & 1.35 & 1.15 \\
\hline \multicolumn{2}{|c|}{$\begin{array}{l}\text { Total CDS } \\
\text { length }(\mathrm{m})\end{array}$} & 1.21 & 0.89 & 0.72 & 0.56 & 0.40 \\
\hline
\end{tabular}

Note: The cells with light grey background are the distances of CDS elements and its complement, where bold printed cells are distances CDS complement elements, italic printed cells are the distance CDS original elements. The cells with white back ground are improve complement elements, dark grey back ground cells are the improved original elements.

\section{Arrays Realization and Measurement}

Considering that a longer array will requires a longer free space distance, in order to comply with far-field conditions and a relatively higher power amplification to handle the related path loss and to address the practicality of manufacturing, it has been chosen to manufacture a CDS $(19,9,4)$ as shown in Table II. Aperture utilization of the linear array $U$ is the ratio between occupied length of array to total length of the array and it is define as: 


$$
U=\frac{\sum_{i=1}^{N} l_{p}(i)}{L}
$$

where $U$ is utilization of total length of the aperture in $\%, l_{p}$ is the single length of the patch, $L$ is total interleaved linear array length, $N$ is the total number of antenna elements. This linear array construction delivered total aperture length utilization $55 \%$ as shown in Table IV. An improved CDS $(19,9,4)$ interleaved array has been manufactured, where two sets of a six antenna element were added and placed at a symmetrical distance with respect to the origin of the CDS $(19,9,4)$ sub-array and its complement.

\section{III.1. Array Measurement Setup}

The far-field radiation pattern of the antennas has been determined using building rooftops with approximately

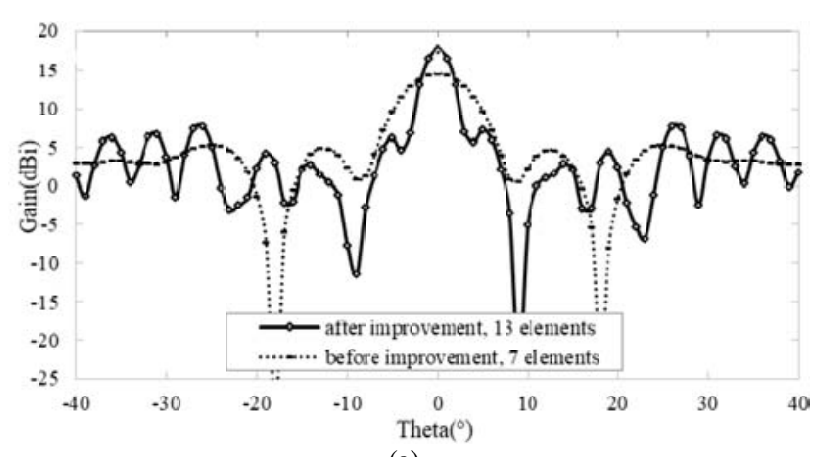

(a)

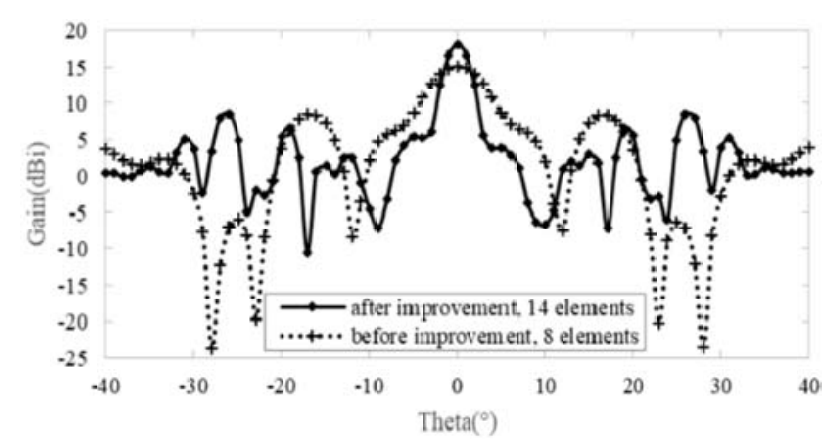

(b)

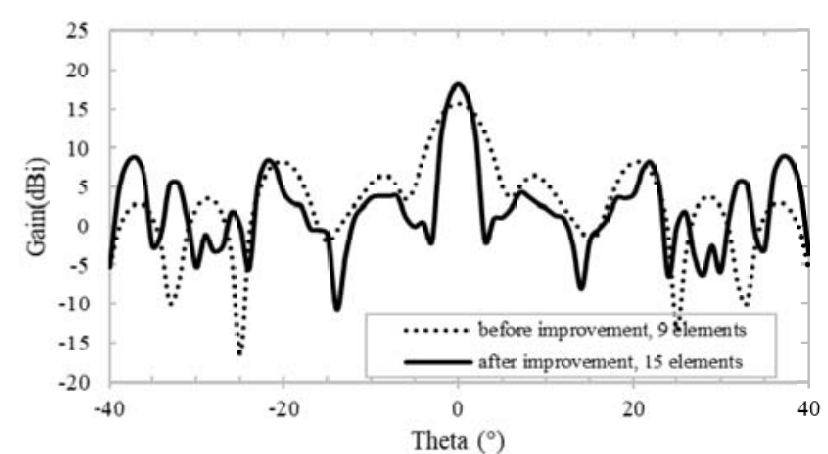

(c)
150 metres between the array antenna being tested and the receiving standard measuring antenna. A $20 \mathrm{dBm}$ wide-band power amplifier has been placed at the transmitting array antenna, whereas a standard horn antenna followed by a $50 \mathrm{dBi}$ gain $45 \mathrm{~K}$ noise temperature $\mathrm{C}$-band amplifier has been inserted at the receiver in order to combat an approximately $88 \mathrm{~dB}$ calculated path loss. A spectrum analyser has been used to measure the received signal. A direct current motor rotated the antenna over the $\pm 40^{\circ}$ azimuth range. In order to provide equal power excitation, three power dividers with a frequency range of 3.5-4.2 GHz have been used, one two way and two 16-way power divider units. One of the 16- way power divider ports was terminated with a 50 -Ohm termination in order to achieve a 15 equal power excitation. The measured array gain must account for the loss of the feeding network of the feeding network. In order to avoid measuring associated path losses, an antenna substitution measurement method is used by means of a calibrated horn with known performance.

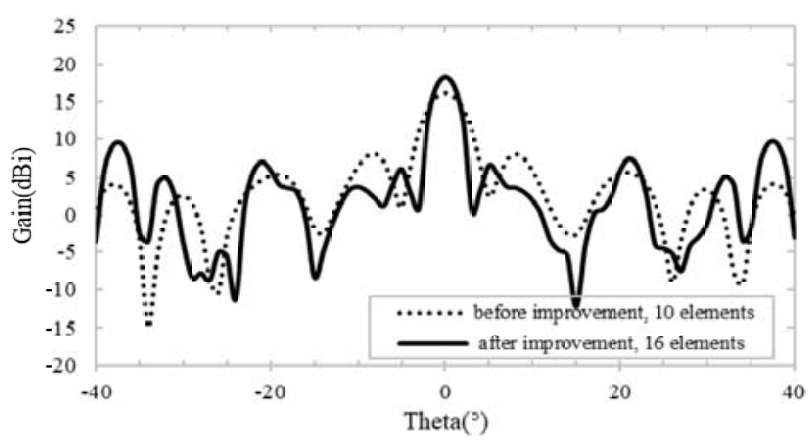

(d)

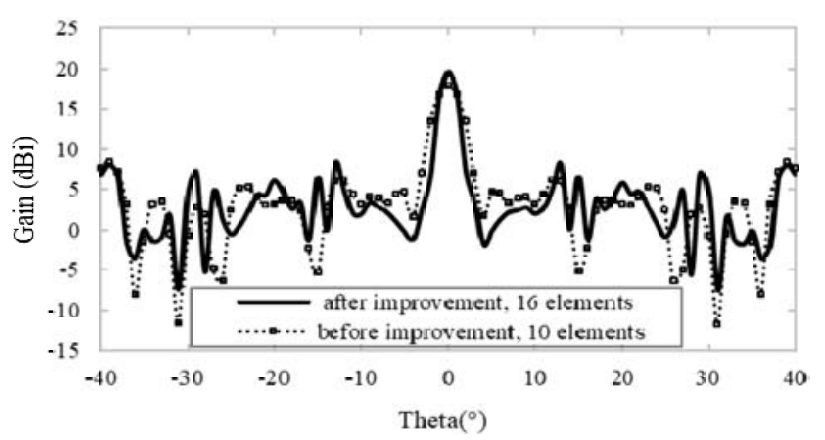

(e)

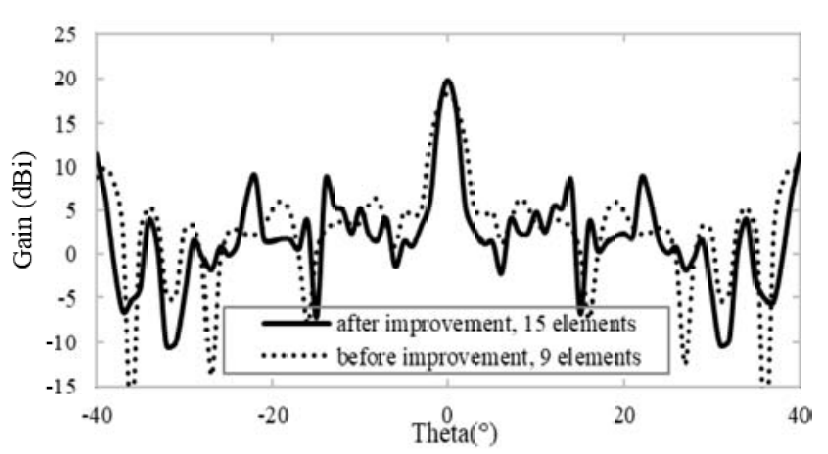

(f)

Figs. 3. Computer simulation results of the Radiation Pattern of arrays before and after improvement. (a) CDS(19,9,4);

(b) $\operatorname{CDS}(15,7,3)$ complement; (c) $\operatorname{CDS}(19,9,4)$; (d) CDS(19,9,4) complement, (e) CDS(31,15,7); (f) CDS(31,15,7) complement 


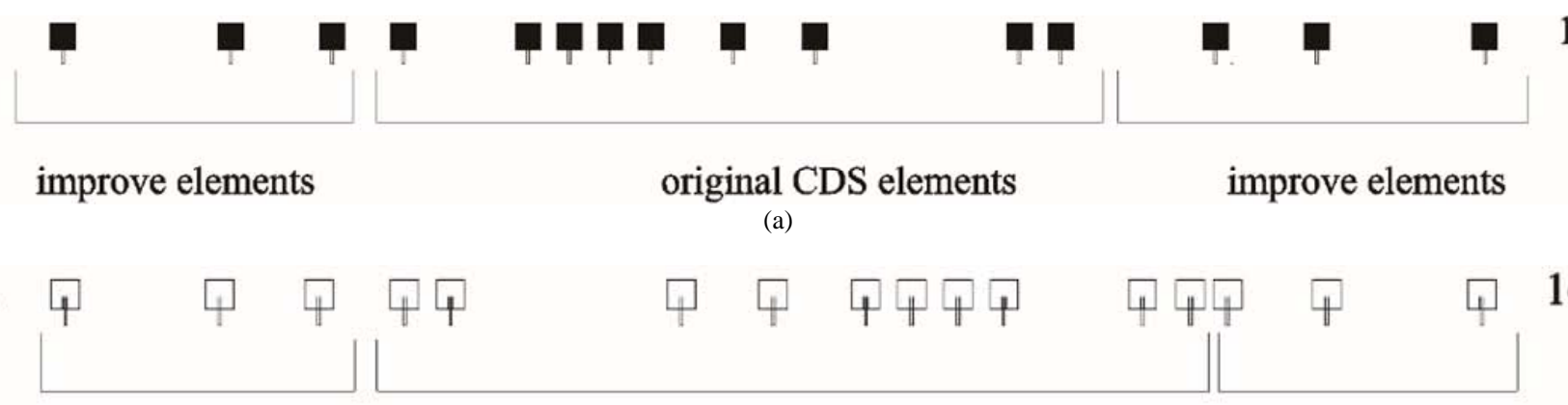

\section{improve elements}

complement CDS elements

(b)

1

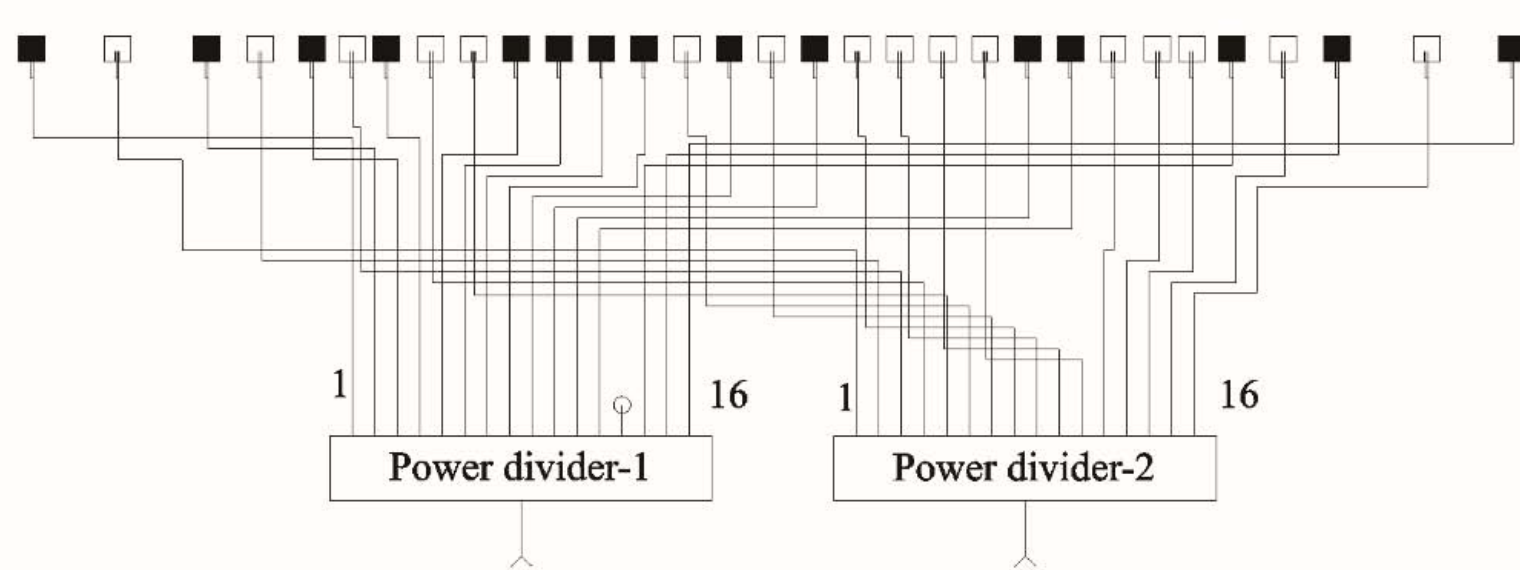

Improved complement CDS array

(c)

Figs. 4. Elements placement of the improved interleaved CDS $(19,9,4)$ array antenna (a) improved original CDS $(19,9,4)$ array, (b) improved complement CDS(19,9,4) array. (c) interleaved improved CDS $(19,9,4)$ array

TABLE III

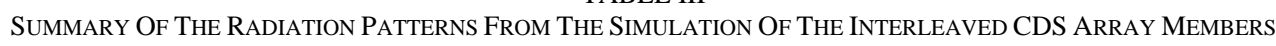
BEFORE AND AFTER THE ADDITION OF THE IMPROVED ELEMENTS

\begin{tabular}{|c|c|c|c|c|c|c|c|c|c|c|c|c|}
\hline \multirow[t]{2}{*}{ Array } & & \multicolumn{2}{|c|}{ Number of element } & \multicolumn{3}{|c|}{ Angular width $\left({ }^{\circ}\right)$} & \multicolumn{3}{|c|}{ Main lobe magnitude (dB) } & \multicolumn{3}{|c|}{$\begin{array}{c}\text { Peak Side lobe level }(\mathrm{dB})<8^{\circ} \\
\text { from main lobe }\end{array}$} \\
\hline & & before & after & before & after & impr & before & after & impr & before & after & impr \\
\hline \multirow{2}{*}{ CDS $(11,5,2)$} & ori & 5 & 11 & 8.6 & 3.4 & 5.2 & 13.9 & 17.9 & 4.0 & -4.1 & -15.9 & 11.8 \\
\hline & comp & 6 & 12 & 8.5 & 3.3 & 5.2 & 14.5 & 17.6 & 3.1 & -6.4 & -16.5 & 10.1 \\
\hline \multirow{2}{*}{ CDS $(15,7,3)$} & ori & 7 & 13 & 8.0 & 3.2 & 4.8 & 14.6 & 17.7 & 3.1 & -10.0 & -11.4 & 1.4 \\
\hline & comp & 8 & 14 & 7.6 & 3.0 & 4.6 & 15.1 & 18.0 & 2.9 & -11.3 & -12.4 & 1.1 \\
\hline \multirow{2}{*}{ CDS $(19,9,4)$} & ori & 9 & 15 & 5.4 & 2.7 & 2.7 & 15.7 & 18.2 & 2.5 & -9.1 & -14.0 & 4.9 \\
\hline & comp & 10 & 16 & 4.8 & 2.7 & 2.1 & 16.1 & 18.5 & 2.4 & -8.0 & -14.5 & 6.5 \\
\hline \multirow{2}{*}{$\operatorname{CDS}(23,11,5)$} & ori & 11 & 17 & 4.9 & 2.3 & 2.6 & 16.1 & 18.6 & 2.5 & -11.0 & -16.9 & 5.9 \\
\hline & comp & 12 & 18 & 4.2 & 2.2 & 2.0 & 16.5 & 18.8 & 2.3 & -13.0 & -15.0 & 2.0 \\
\hline \multirow{2}{*}{$\operatorname{CDS}(31,15,7)$} & ori & 15 & 21 & 3.4 & 1.9 & 1.5 & 18.5 & 20.3 & 1.8 & -9.3 & -13.1 & 3.8 \\
\hline & comp & 16 & 22 & 2.8 & 1.8 & 1.0 & 18.8 & 20.5 & 1.7 & -12.0 & -15.4 & 3.4 \\
\hline
\end{tabular}

Note: ori=original CDS array, comp= complement CDS array, impr = improvement

The measured gain must account for both the loss of the cable and the insertion loss of the array's feeder network, which contains cables and connector losses and the insertion loss associated with the 1:16 power divider.

Figs. 4(a) and (b) show the realization of the improved CDS $(19,9,4)$ arrays, where after improvement each one has 15 and 16 elements. Fig. 4(c) shows the improved array's antenna after interleaving and its feeding network diagram respectively. The manufactured interleaved array and turning table are presented in Fig. 5(a), whereas the horn for completeness of the array measurement system is presented in Figs. 5(b).

\section{III.2. Measurement Results and Discussion}

The first measurement has aimed to compare the radiation patterns of the simulation and the measurement of the arrays. The radiation patterns from the improved original CDS $(19,9,4)$ array and the improved complementary CDS $(19,9,4)$ array are presented in Figs. 6 and summarized in Table V. The main lobe gain measurement and the simulation results differ by less 
than $0.9 \mathrm{~dB}$ due to the precision of the measurement system and the efficiency of the realized array.

The gain in the improved original CDS with 16 patches is slightly greater than the gain in the improved array with 15 patches. The achieved side lobe performances are better than before the improvement, but the individual side lobes are worse than the approximation of the optimum tapered illumination due to the use of the CDS in the middle part.

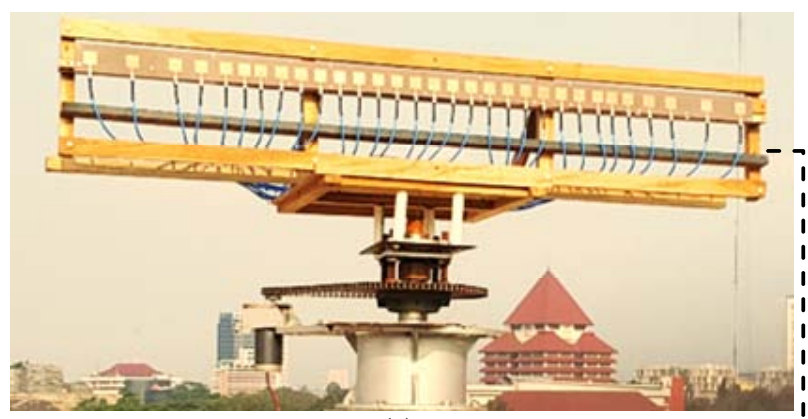

(a)

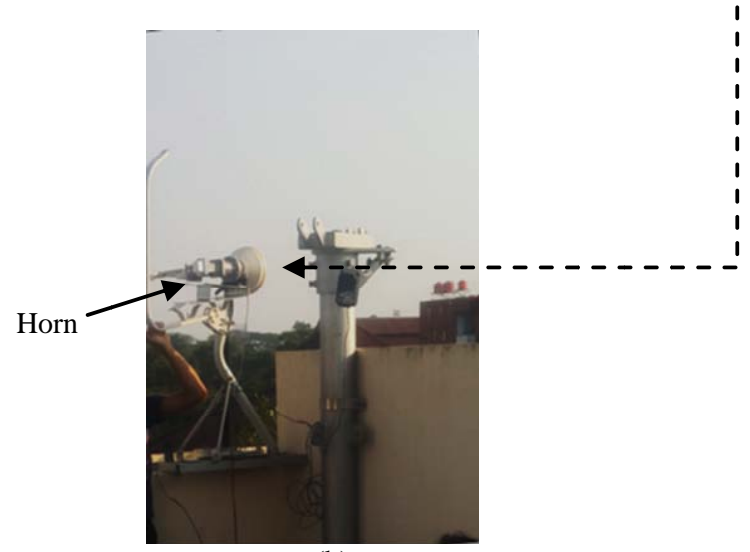

(b)

Figs. 5. (a) Realization of the improved interleaved CDS $(19,9,4)$ array antenna and its rotating table. (b) Horn

The side lobe fall-off rate of the measured arrays has been faster than in the simulation because the radiation pattern is the result of the multiplication of the element factor of the patch with the array factor.

A better antenna element is needed in order to achieve a faster side lobe fall-off rate. Lower side lobe levels may be achieved by using a longer CDS or more improved patches, both of which will result in longer total length interleaved arrays.

The second measurement has aimed to compare the radiation patterns of the measurement of the original and complement CDS arrays before and after the improvements, as shown in Figs. 7.

The results are summarized in Table VI, which shows that after improvement, the side lobes have been suppressed by $3.7 \mathrm{~dB}$ and $1.66 \mathrm{~dB}$, whereas the beam widths have been both narrowed by 3 degrees. The radiation pattern is the result of the array factor and the element factor.

The array factor is determined by the space tapering. Different tapering functions can be employed and will be investigated in future research activities.

The results of this study have demonstrated the effectiveness of this method for interleaving two arrays sharing one aperture for a multi-beam antenna, with each one containing a narrowed beam width and decreased side lobes.

TABLE IV

APERTURE UTILIZATION CALCULATION OF THE IMPROVE INTERLEAVED CDS $(19,9,4)$ LINEAR ARRAY CDS (19,9,4) Linear Array Aperture Utilization

\begin{tabular}{|c|c|c|c|c|}
\hline \multicolumn{5}{|c|}{ CDS $(19,9,4)$ Linear Array Aperture Utilization } \\
\hline Array & $\begin{array}{c}\text { Total } \\
\text { number of } \\
\text { elements }(\mathbf{N})\end{array}$ & $\begin{array}{l}\text { Array } \\
\text { Length L } \\
(\mathbf{m})\end{array}$ & $\begin{array}{l}\text { Occupied } \\
\text { Aperture } \\
(\mathbf{m})\end{array}$ & $\begin{array}{c}\text { Aperture } \\
\text { Utilization U } \\
(\%)\end{array}$ \\
\hline $\begin{array}{c}\text { Improved CDS } \\
\text { Original }\end{array}$ & 15 & 1.23 & 0.37 & $30 \%$ \\
\hline $\begin{array}{l}\text { Improved CDS } \\
\text { Complement }\end{array}$ & 16 & 1.39 & 0.39 & $28 \%$ \\
\hline $\begin{array}{c}\text { Improve } \\
\text { interleaved CDS }\end{array}$ & 31 & 1.39 & 0.76 & $55 \%$ \\
\hline
\end{tabular}

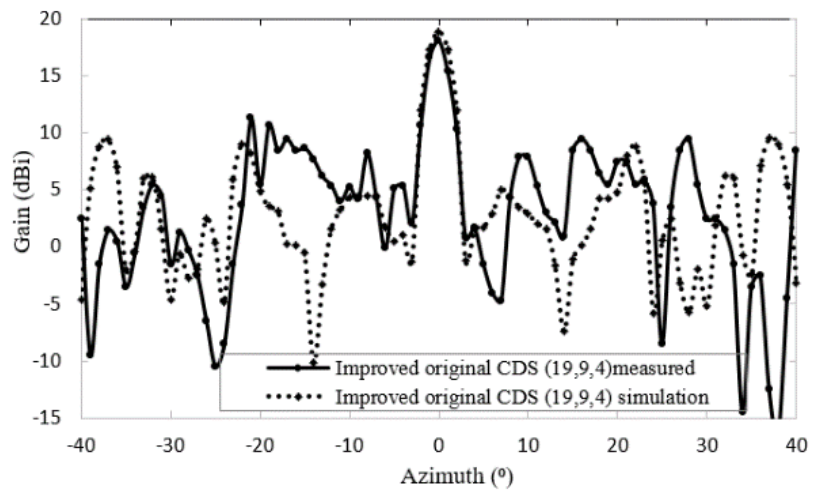

(a)

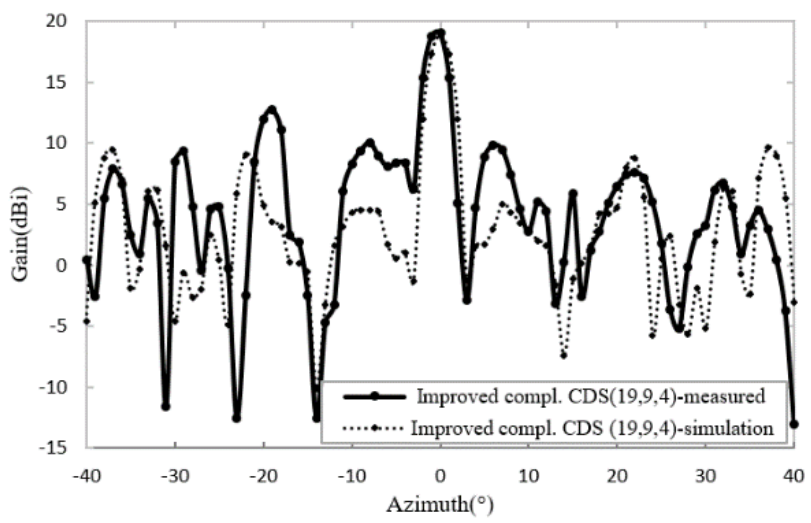

(b)

Figs. 6. Comparison of the CST array simulation and measurement results: (a) improved original CDS $(19,9,4)$ array with a feeder and (b) improved complementary CDS $(19,9,4)$ array

TABLE V

COMPARISON OF THE RADIATION PATTERNS FOR THE IMPROVED INTERLEAVED CDS $(19,9,4)$ ARRAYS

\begin{tabular}{|c|c|c|c|c|}
\hline \multicolumn{5}{|c|}{ CDS(19.9,4) } \\
\hline CDS(19.9,4) & & Original & Co & ment \\
\hline \multicolumn{5}{|c|}{ Radiation PatternSimulationMeasurementSimulationMeasurement } \\
\hline Gain $(\mathrm{dBi})$ & 18.9 & 18.08 & 18.86 & 18.78 \\
\hline Angular width $\left({ }^{\circ}\right)$ & 2.7 & 2.7 & 3 & 3 \\
\hline $\begin{array}{l}\text { 1st sidelobe level } \\
(\mathrm{dB})\end{array}$ & 9.84 & 7.7 & 13.823 & 8.7 \\
\hline
\end{tabular}




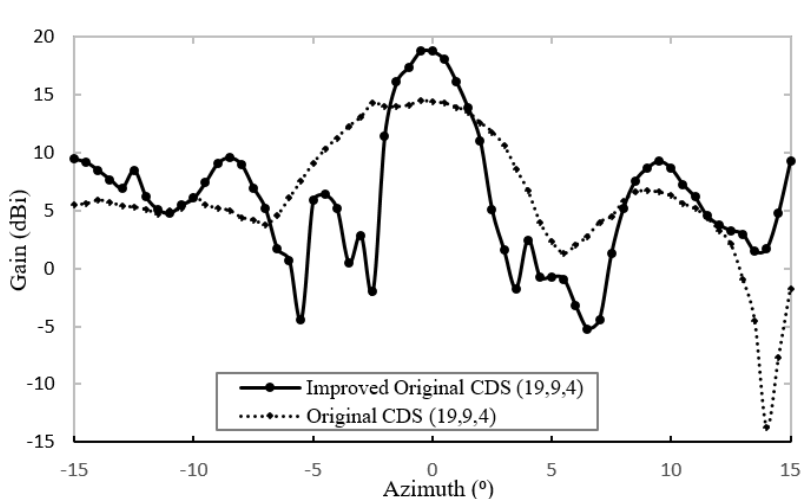

(a)

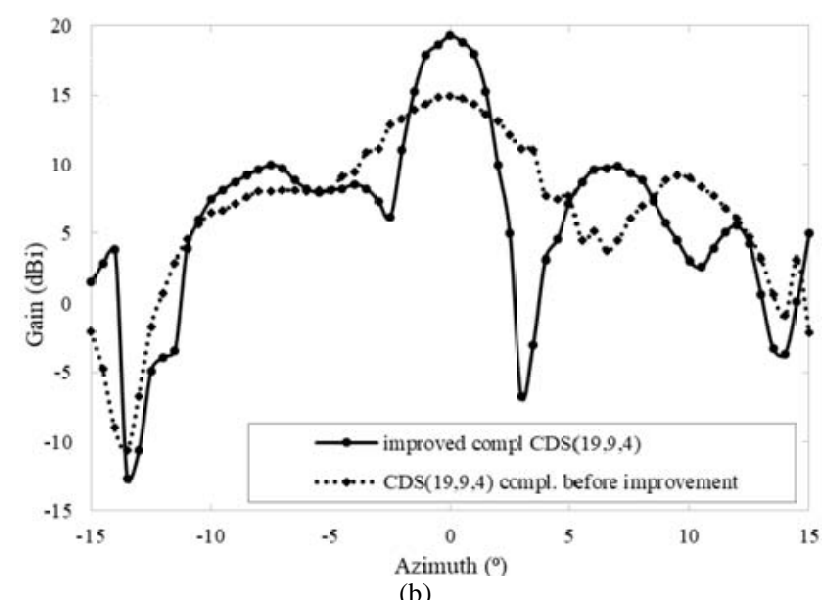

(b)

Figs. 7. Radiation pattern measurement results before and after the improvements: (a) CDS $(19,9,4)$ and (b) complementary CDS $(19,9,4)$

TABLE VI

COMPARISON OF THE RADIATION PATTERNS FOR THE CDS $(19,9,4)$ ARRAYS BEFORE AND AFTER IMPROVEMENT

\begin{tabular}{cccc}
\hline \hline \multicolumn{5}{c}{ CDS (19.9,4) Radiation Pattern } \\
\hline \multicolumn{5}{c}{ Gain (dBi) } & $\begin{array}{c}\text { Angular } \\
\text { width }\left({ }^{\circ} \text { ) }\right.\end{array}$ & $\begin{array}{c}\text { Peak sidelobe } \\
\text { level (dB) }\end{array}$ \\
Original CDS array & \\
Before improvement & 13.68 & 5 & -7.8 \\
After improvement & 17.98 & 2 & -11.5 \\
Improvement & 4.3 & 3 & 3.7 \\
\multicolumn{5}{c}{ Complement CDS array } & \\
Before improvement & 14.86 & 5.5 & -7.27 \\
After improvement & 18.43 & 2.5 & -8.93 \\
Improvement & 4.3 & 3 & 1.66 \\
\hline \hline
\end{tabular}

\section{Conclusion}

An improved interleaved linear CDS has been designed and simulated. The measurements of the arrays have showed that this method is capable of improvements to their gain, beam width, and side lobe levels. It is demonstrated that compared to the original CDS performance, the improved arrays have a narrower beam width of least 3 degrees and a side lobe level suppression of at least $1.66 \mathrm{~dB}$, with a difference of gain of the main lobe less than $0.9 \mathrm{~dB}$ between the simulations and measurement. The method has showed an increase to $55 \%$ of aperture utilization compared to the previous individual arrays before interleaving, where the latter has achieved only $30 \%$ and $28 \%$, subsequently for Improved Original CDS and Improve Complement CDS.

Therefore, it is concluded that the proposed method is an effective interleaved method for aperture sharing. The proposed method also provides flexibility in the design of interleaved array of a given aperture despite the limited availability of CDS. Future work will include the introduction of different polarizations for the arrays, the utilization of different tapering functions, the introduction of different antenna elements and an extension method to planar arrays.

\section{Acknowledgements}

This project is supported by: Hibah Tugas Akhir Mahasiswa Doktor Universitas Indonesia. Nomor: 1345/UN2.R3.1/HKP.05.00/2018

\section{References}

[1] T. N. Kaifas, D. G. Babas, G. Toso, and J. N. Sahalos, Multibeam antennas for global satellite coverage: theory and design, IET Microwaves, Antennas \& Propagation, vol. 10, 2016, pp. 14751484.

[2] T. N. Kaifas, D. G. Babas, G. Toso, and J. N. Sahalos, Tx/Rx multibeam satellite antenna array design assesment on a single aperture, in 2014 8th European Conference on Antennas and Propagation (EuCAP), The Hague, NL, 2014, pp. 1805-1809.

[3] J. M. Montero, A. M. Ocampo, and N. J. G. Fonseca, C-band multiple beam antennas for communication satellites, IRE Trans. Antennas Propagation, vol. 63, January 2015, pp. 1263-1275.

[4] B. Palacin, N. J. G. Fonseca, M. Romier, R. Contreres, J. C. Angevain, G. Toso, et al., Multibeam antennas for very high throughput satellites in Europe: technologies and trends, in 2017 11th European Conference on Antennas and Propagation (EUCAP), Paris, France, 2017, pp. 2413-2417.

[5] P. Angeletti, C. Mangenot, and G. Toso, Recent advances on array antennas for multibeam space applications, in 2013 IEEE Antennas and Propagation Society International Symposium (APSURSI), Orlando, FL, 2013, pp. 2233-2234.

[6] G. Toso, P. Angeletti, and C. Mangenot, Multibeam antennas based on phased arrays: an overview on recent ESA developments, in The 8th European Conference on Antennas and Propagation (EuCAP 2014), The Hague, NL, 2014, pp. 178-181.

[7] S. Rao, C. C. Hsu, and J. Wang, Common aperture satellite antenna system for multiple contoured beams and multiple spot beams, in 2010 IEEE Antennas and Propagation Society International Symposium, Berlin, Germany, 2010, pp. 1-4.

[8] C. I. Coman, I. E. Lager, and L. P. Ligthart, Design considerations in sparse array antennas, in 2006 European Radar Conference, Manchester, UK, 2006, pp. 72-75.

[9] $\mathrm{L}$. Li and $\mathrm{F}$. Li, The design of sparse antenna array. arXiv preprint. arXiv:0811.0705, 2008.

[10] M. C. Vigano, G. Toso, P. Angeletti, I. E. Lager, A. Yarovoy, and D. Caratelli, Sparse antenna array for Earth-coverage satellite applications, in 2010 Proceedings of the Fourth European Conference on Antennas and Propagation (EuCAP), Barcelona, Spain, 2010, pp. 1-4.

[11] G. Toso, C. Mangenot, and A. G. Roederer, Sparse and thinned arrays for multiple beam satellite applications, in The Second European Conference on Antennas and Propagation, EuCAP 2007, Edinburgh, UK, 2007, p. 566.

[12] O. M. Bucci, T. Isernia, A. F. Morabito, S. Perna, and D. Pinchera, Aperiodic arrays for space applications: an effective strategy for the overall design, in 2009 3rd European Conference on Antennas and Propagation, Berlin, Germany, 2009, pp. 20312035.

[13] P. Angeletti and G. Toso, Aperiodic arrays for space applications: a combined amplitude/density synthesis approach, in 2009 3rd 
European Conference on Antennas and Propagation, Berlin, Germany, 2009, pp. 2026-2030.

[14] W. Doyle, On approximating linear array factors. Fort Belvoir, VA: Ft. Belvoir Defense Technical Information Center, 1963.

[15] E. T. Rahardjo, E. Sandi, and F. Y. Zulkifli, Design of linear sparse array based on the Taylor line source distribution element spacing, in 2017 IEEE Asia Pacific Microwave Conference (APMC), Kuala Lumpar, Malaysia, 2017, pp. 61-64.

[16] R. L. Haupt, Interleaved thinned linear arrays, IEEE Trans. Antennas Propagation, vol. 53, September 2005, pp. 2858-2864.

[17] L. Qi, Z. Long, S. Gao, P. Cruz, J. Wonhoon, S. Pires, et al., Interleaved dual-band circularly polarized active array antenna for satellite communications, in 2015 9th European Conference on Antennas and Propagation (EuCAP), Lisbon, Portugal, 2015, pp. $1-5$.

[18] G. Oliveri, P. Rocca, and A. Massa, Interleaved linear arrays with difference sets, Electron. Letters, vol. 46, March 2010, pp. 323324.

[19] C. I. Coman, I. E. Lager, and L. P. Ligthart, Multifunction antennas - the interleaved sparse sub-arrays approach, in 2006 European Radar Conference, Manchester, UK, 2006, pp. 17941797.

[20] O. M. Bucci, M. D'Urso, T. Isernia, P. Angeletti, and G. Toso, Deterministic synthesis of uniform amplitude sparse arrays via new density taper techniques, IEEE Trans. Antennas Propagation, vol. 58, March 2010, pp. 1949-1958.

[21] O. M. Bucci, Active arrays for satellite communications, in 2012 Loughborough Antennas \& Propagation Conference (LAPC), Loughborough, UK, 2012, pp. 1-4.

[22] G. Swenson and Y. Lo, The University of Illinois radio telescope, IRE Trans. Antennas Propagation, vol. 9, March 1961, pp. 9-16.

[23] D. G. Leeper, Isophoric arrays-massively thinned phased arrays with well-controlled sidelobes, IRE Trans. Antennas Propagation, vol. 47, December 1999, pp. 1825-1835.

[24] C. Trampuz, M. Simeoni, I. E. Lager, and L. P. Ligthart, Complementarity based design of antenna systems for FMCW radar, in European Radar Conference, Amsterdam, Netherlands, 2008, pp. 216-219.

[25] C.-X. Mao, S. Gao, Q. Luo, T. Rommel, and Q.-X. Chu, Low-cost $\mathrm{X} / \mathrm{Ku} / \mathrm{Ka}$-band dual-polarized array with shared aperture, IEEE Transactions on Antennas and Propagation, vol. 65, 2017, pp. 3520-3527.

[26] C.-X. Mao, S. Gao, Y. Wang, Q.-X. Chu, and X.-X. Yang, DualBand Circularly Polarized Shared-Aperture Array for C-/X-Band Satellite Communications, IEEE Transactions on Antennas and Propagation, vol. 65, 2017, pp. 5171-5178.

[27] Kumar, K., Pavani, M., Design of a Compact Rectangular Patch Antenna Using Defected Ground Structure, (2017) International Journal on Communications Antenna and Propagation (IRECAP), 7 (4), pp. 282-289. doi:https://doi.org/10.15866/irecap.v7i4.12389

[28] Kumari, R., Kumar, M., Microstrip Patch Multiband Antenna for C-Band, X-Band and Ku-Band Applications, (2013) International Journal on Communications Antenna and Propagation (IRECAP), 3 (3), pp. 176-180.

[29] Altamirano, C., de Almeida, C., Inter-User Interference Reduction in Massive MIMO for Linear and Planar Arrays, (2019) International Journal on Communications Antenna and Propagation (IRECAP), 9 (1), pp. 30-35. doi: https://doi.org/10.15866/irecap.v9i1.12702

[30] K. W. Cattermole, Mathematical foundation for communication engineering. Pentech Press, UK: Pentech Press, 1985.

[31] D. G. Leeper, Isophoric arrays-massively thinned phased arrays with well-controlled sidelobes, IEEE Transactions on Antennas and Propagation, vol. 47, 1999, pp. 1825-1835.

[32] C. A. Balanis, Antenna theory analysis and design vol. 3rd Edition. Hoboken, NJ: Wiley, 2005.

[33] MATLAB for deep learning, Available: https://www.mathworks.com

\section{Authors' information}

Department of Electrical Engineering, Universitas Indonesia

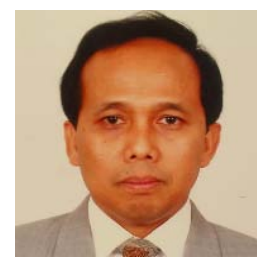

Bambang Dewandaru, was born 5 December 1956, in Malang, Indonesia. He received Ir (insinyur) degree from Institut Teknologi Bandung, Indonesia, in 1981, Post Graduate Diploma in telecommunication and information systems, from Essex University, Colchester, England, 1988, and Master of Science in Electrical Engineering (MSEE) degree from Northeastern University, Boston, Massachusetts, USA, 1993. He joined PT Telekomunikasi Indonesia Tbk (TELKOM), a government owned telecomunication company of Indonesia, in 1981, where he hold various positions, included general manager of the satellite communication division, and director of TELKOM's subsidiaries companies. He is the founder of PT GTA, a private company to manufacture satellite and radar antennas, in 1987. He joined the Antenna Propagation and Microwave Research Group (AMRG) UI since 2014. His current research is in wave propagation and antennas. Mr Dewandaru is a member of IEEE.

E-mail: bambang.dewandaru@ieee.org

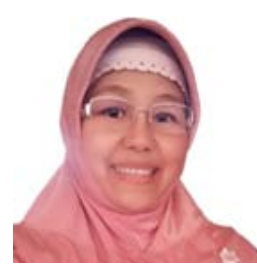

Fitri Yuli Zulkifli, was born in Banda Aceh, 19 July 1974. She received her Bachelor (1997) and $\mathrm{PhD}$ degree (cumlaude, 2009) from Electrical Engineering Department, Universitas Indonesia. While her MSc degree she received from Telecommunication and Information Technology Department, University of Karlsruhe, Germany, 2002. Her research interests are Antenna, Propagation, Microwave and in the field of Electromagnetic. She joined the Antenna Propagation and Microwave Research Group (AMRG) UI since 1997 and has become lecturer since 1998. She has published more than 170 papers in international/national journals and conference proceedings and has been involved in more than 40 granted researches. With all of here activities, in 2011 she was granted "Best Lecturerer Award (Dosen Berprestasi)" from Universitas Indonesia and achieved 4th place "Best Lecturerer Award" from Indonesia in the same year.

She is involved in many teamwork activities and also involved as organizing committee in many seminars and workshops. She has been the Secretary and Treasurer of IEEE joint chapter MTT/AP and in 2010 as Treasurer of the same joint chapter, then from 2011-2012 she has become the joint chapter chair. 2013-2016 she was coordinator technical activity in IEEE Indonesia section as well as executive committee of joint chapter MTT/AP-S. Dr Zulkifli was the IEEE Indonesia Section Chair in 2017-2018.

E-mail: yuli@eng.ui.ac.id

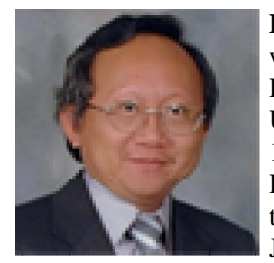

Eko Tjipto Rahardjo, (corresponding author) was born in Pati, Indonesia, on April 22, 1958. $\mathrm{He}$ received the Ir. (Insinyur) degree from Universitas Indonesia, Jakarta, Indonesia, in 1981, the MS degree from the University of Hawaii at Manoa, Honolulu, USA, in 1987, and the PhD degree from Saitama University, Urawa, Japan, in 1996, all in electrical engineering. He joined to the Department of Electrical Engineering Universitas Indonesia since 1982 as a teaching assistant. Since 2005 he has been appointed as Professor in electrical engineering. He has been as Chairman of University Senate of Universitas Indonesia in 2011-2012. $\mathrm{He}$ has also been as Head of Electrical Engineering Department, Universitas Indonesia (2004-2008). He was Executive Director of the Quality Undergraduate Education (QUE) in the Department of Electrical Engineering Universitas Indonesia (1999-2004), and was Head of Telecommunication Laboratory Universitas Indonesia (19972004). Since 2003, he has been Director of Antenna propagation and Microwave Research Group (AMRG), Universitas Indonesia. He has been recipient of the Indonesian government scholarship through MUCIA (1984-1987); the Hitachi Scholarship (1992-1996); the Young Researcher's Award from the Universitas Indonesia (1996), the 2nd winner of Best Researcher Award in Science and Technology 
Universitas Indonesia (2009) and the 2nd winner of Best Teaching Award Universitas Indonesia (2010). His research interests include antenna engineering, wave propagation, microwave circuits and communication system and telecommunication system regulations. He has been published and presented more than a hundred research papers both national and international journals and symposiums. Dr. Rahardjo is members of IEEE Antenna and Propagation Society (AP-S) and IEEE Microwave Theory and Technique Society (MTT-S). He was founder of IEEE Joint Chapter MTT-S/AP-S Indonesia. He has served as president of IEEE Joint Chapter MTT-S/AP-S, IEEE Indonesia Section in 2009-2010 and 2014-2015. He is also a member of International Steering Committee (ISC) of Asia Pacific Microwave Conference (APMC) since 2010, General Chairman of Indonesia Malaysia Microwave and Antenna Conference (IMMAC) 2010 held in Jakarta, General Chairman of Indonesia Japan Joint Scientific Symposium (IJJSS) 2010 held in Bali, General co-Chairman of Indonesia Japan Joint Scientific Symposium (IJJSS) 2012 held in Chiba, Japan, and as a member of International Advisory Board of International Symposium on Antenna and Propagation (ISAP) since 2012.

E-mail: eko@eng.ui.ac.id 